$$
\text { Special Article }
$$

\title{
DIFFERENCES IN THE USE OF PSYCHIATRIC OUTPATIENT SERVICES BETWEEN THE UNITED STATES AND ONTARIO
}

\author{
Ronald C. Kessler, Ph.D., Richard G. Frank, Ph.D., Mark Edlund, B.S., Steven J. Katz, M.D., M.P.H., \\ Elizabeth Lin, Ph.D., ANd Philip Leaf, Ph.D.
}

\begin{abstract}
Background The relation between health insurance and the use of mental health services is unclear. We compared the use of outpatient services for psychiatric problems in the United States and Ontario, Canada, among young and middle-aged adults according to self-reports of disorders listed in the Diagnostic and Statistical Manual of Mental Disorders (third edition, revised) and to other indicators of need.

Methods We analyzed two general-population surveys carried out separately in the United States and Ontario in 1990 that used identical assessments of need for services and questions about their use by persons 15 to 54 years of age.

Results Respondents in the United States were significantly more likely than those in Ontario to report having had psychiatric disorders, poor mental health, or workdays lost or cut short because of psychiatric problems in the previous year. A significantly higher proportion of respondents in the United States (13.3 percent) than in Ontario (8.0 percent) had obtained outpatient treatment in the previous 12 months for psychiatric problems. However, an analysis of subgroups found that the higher probability of the use of services in the United States was confined to people with less severe mental illness. The average number of visits did not differ significantly between the two countries among patients who had similar numbers of psychiatric disorders over the same time periods. There was a stronger match in Ontario than in the United States between the use of services and the measures of perceived need we considered.
\end{abstract}

Conclusions Although the mental health care system in the United States provides treatment to a larger proportion of the population than that in Ontario, the match between some measures of need and treatment is not as strong in the United States. Any plans to expand coverage for psychiatric disorders in the United States must address this problem. (N Engl J Med 1997;336:551-7.)

(C)1997, Massachusetts Medical Society.
$\mathrm{T}$

HE U.S. mental health care system has been criticized for restricting the access to care of uninsured people who are unable to pay. ${ }^{1}$ However, some believe that too many mental health care resources are already devoted to people with low levels of need and that this trend will only increase if access is expanded. ${ }^{2}$ Proponents of expanded coverage have responded that there is little evidence of unnecessary use of services in countries that offer broad mental health coverage. $^{3}$

The Canadian experience has figured prominently in this debate. Canada approximates the United States in economic development, history, ethnicity, and geography 4,5 but expends a relatively lower percentage of its gross national product on health care, despite having universal coverage. ${ }^{3,6}$ The lack of comparative data on whether Canadians with serious psychiatric problems are more likely than their counterparts in the United States to receive treatment as a result of enhanced access has hampered close evaluation of the Canadian mental health care system. We address this lack with data from two recent population surveys of psychiatric disorders and the use of services that were conducted in the United States and the Canadian province of Ontario. Analyzing a single province is appropriate because the Canadian health care system is organized at the provincial level. Ontario is of particular interest because it is not only the largest province (home to 36 percent of the Canadian population ${ }^{7}$ ) but also similar to the United States in terms of key sociodemographic variables: urbanization, industrialization, ${ }^{7,8}$ and the dis-

From the Department of Health Care Policy, Harvard Medical School, Boston (R.C.K., R.G.F.); the School of Medicine and the Department of Health Services Management and Policy, School of Public Health (M.E.), and the Department of Internal Medicine, School of Medicine, and the Department of Health Services Management and Policy, School of Public Health (S.J.K.), University of Michigan, Ann Arbor; the Department of Psychiatry, University of Toronto, and the Health Systems Research Unit, Clarke Institute of Psychiatry, Toronto (E.L.); and the Department of Mental Hygiene, Johns Hopkins University, Baltimore (P.L.). Address reprint requests to Dr. Kessler at the Department of Health Care Policy, Harvard Medical School, 25 Shattuck St., Parcel B, lst Fl., Boston, MA 02115. 
tribution of physicians $(2.2$ per 1000 population in Ontario vs. 2.1 per 1000 in the United States $\left.{ }^{9,10}\right)$. Total per capita expenditures for mental health and the ratio of institutionalized to noninstitutionalized patients in Ontario are similar to those in Canada's other provinces. ${ }^{11}$

Ontario and the United States control the use of services by different strategies. Ontario's comprehensive mental health insurance features cost sharing and does not limit the number of visits ${ }^{12}$; however, only physicians are reimbursed by the Provincial Insurance Plan, although some psychologists and psychiatric social workers are funded through salaried positions in health centers. ${ }^{13,14}$ The United States, in comparison, limits demand. Roughly 16 percent of the population is uninsured, and mental health coverage is often limited even for the insured. ${ }^{15} \mathrm{Al}$ though an extensive public mental health system provides care at little or no cost to the poor and the uninsured, supply-side controls severely limit access. As people with limited financial resources are constrained much more than others, the strongest barriers to access affect the segment of society with the highest rates of disorders. ${ }^{16,17}$ Few safeguards limit excessive use of services by people with ample financial resources. ${ }^{1,18}$

In the light of these markedly different strategies, we expected to find a difference between the United States and Ontario in the number of people receiving treatment as well as in the number of visits per patient. We were especially interested in whether such differences would be more pronounced among patients with low levels of need.

\section{METHODS}

\section{Samples}

The data come from the U.S. National Comorbidity Survey $(\mathrm{NCS})^{16}$ and the Mental Health Supplement to the Ontario Health Survey (OHS) ${ }^{19}$ - household surveys carried out in 1990 with the use of a psychiatric interview that assessed a core set of disorders by means of identical questions about symptoms and the use of services. The NCS also evaluated several additional disorders not considered here, but this was done after assessment of the core disorders. The NCS surveyed people ranging in age from 15 to 54 years, and the OHS supplement surveyed people 15 years of age or older. The analyses reported here are limited to the 15-to-54-year-olds in both surveys.

The NCS was administered to 8098 respondents and had a response rate of 82.4 percent. Questions about the use of services, however, were administered only to a probability sample of 5877 respondents, who are the focus of the present analysis. The supplement to the OHS was administered to a follow-up sample of 9953 random respondents selected from the households that participated in one quarterly administration of the OHS. The OHS response rate for the supplement was 88.1 percent, and of these households 76.5 percent participated in the supplement $(77.8$ percent of those in the 15-to-54-year age range), for an overall response rate of 67.4 percent.

Neither the NCS nor the OHS supplement sampled homeless or institutionalized people, populations known to have high rates of psychiatric disorders. ${ }^{17,20}$ Because these people compose a larger proportion of the population in the United States than in On- tario, $7,8,21,22$ underestimation of the prevalence of disorders in the total population is probably greater in the NCS than in the supplement. However, this bias should be negligible because only a small proportion of the total number of cases occur among these population segments. The average daily proportion of inpatients with psychiatric disorders is only 0.09 percent in the United States $^{8}$ and 0.05 percent in Ontario, ${ }^{21}$ and the proportion of homeless people is no more than 0.01 to 0.02 percent in either country.7,20 These numbers are only 0.3 percent as large as the number of people in the general population estimated in the surveys to have had recent psychiatric disorders - a figure that represents the upper limit of the extent to which the exclusion of these population segments will bias estimates of prevalence.

\section{Diagnostic Assessment}

Diagnoses are based on a modified version of the Composite International Diagnostic Interview (CIDI) ${ }^{23}$ an instrument designed to be used by nonclinicians. Modifications consisted largely of changes in the order of questions, clarifications, and the use of memory-enhancement strategies. ${ }^{16}$ The disorders assessed in both surveys include major depressive disorder with impairment, dysthymia with impairment, mania, generalized anxiety disorder, panic disorder, phobia, antisocial personality disorder, and abuse of or dependence on either alcohol or illicit drugs. All diagnoses were made according to the criteria of the Diagnostic and Statistical Manual of Mental Disorders (third edition, revised) (DSMIII-R) and were based on the CIDI diagnostic computer program. World Health Organization CIDI field trials documented good reliability and validity for all the CIDI diagnoses used here. ${ }^{24}$ To define the degree of psychiatric illness, we classified respondents in four subgroups: those who had had two or more disorders in the previous 12 months, those who had had one disorder in the previous 12 months, those who had had no disorders in the previous 12 months but had a lifetime history of one or more disorders, and those who had no lifetime history of disorders. More complex coding schemes were also explored but yielded results similar to those reported below.

In the field, the NCS and the OHS supplement differed in one administrative respect. The NCS used a "commitment probe" a question designed to measure the subject's commitment to the survey - at the beginning of the diagnostic interview, but the supplement did not. The question was whether the respondents would agree to think carefully and answer honestly. The small number (less than 1 percent) of respondents who responded "no" were excluded from further questions and treated as nonrespondents. On the basis of research showing that the commitment probe can increase the accuracy of reporting, ${ }^{25}$ its use could slightly inflate U.S. estimates of prevalence.

In order to evaluate the possible effect of this potential methodologic variable, we replicated key comparative analyses, using three indirect measures of the need for services. The first is a measure of perceived mental health based on respondents' ratings of their overall mental health as excellent, very good, good, fair, or poor; the responses could not be affected by the commitment probe because the questions about perceived mental health preceded the commitment probe in the interview. The second and third analyses are measures of the numbers of workdays lost or cut short in the previous month as a result of psychiatric problems. These were typically administered an hour after the commitment probe, making it unlikely that the probe would have had an effect on responses.

\section{Use of Outpatient Services}

Respondents were asked about their use of outpatient services to determine the location and number of visits to health care professionals during the previous 12 months for "problems with your emotions or nerves or your use of alcohol or drugs." Mental health specialty contact was defined as either seeing a psychiatrist or psychologist in any setting or seeing an allied health professional (e.g., nurse or social worker) in a psychiatric or addiction- 
treatment setting; general medical contact was defined as seeing a nonpsychiatrist physician in any setting or an allied health professional in a general medical setting. Those were combined into a category of health care contact. Human-services contact was defined as seeing a counselor, social worker, or nurse in a social-service agency; seeing a minister, priest, or rabbi in any setting; seeing some other professional (e.g., school counselor); or using a telephone hotline. Respondents were also asked whether they attended a self-help group for problems with their emotions, nerves, or use of alcohol or drugs.

Although we did not assess the reliability and validity of these reports, previous research has shown that self-reports of the use of outpatient health care services generally underestimate the number of visits documented in medical records and that this trend grows stronger as the recall period increases and the number of visits decreases. ${ }^{26} \mathrm{~A}$ record check conducted as part of the Epidemiologic Catchment Area study confirmed that 85 percent of the respondents who reported general medical visits and 64 percent of those who reported mental health specialty visits during the 12 months before their interviews did in fact make those visits, with 41 percent reporting a number of visits that differed from their records by no more than one visit. ${ }^{27}$

\section{Statistical Analysis}

The data were weighted to adjust for variations in the probability of selection and differential nonresponse. ${ }^{28}$ Standard errors were estimated with the use of the Taylor series linearization method $^{29}$ implemented in the PSRATIO program of the Osiris software package. ${ }^{30}$ Wald chi-square tests were used to evaluate the significance of interactions between countries and levels of need in predicting the use of services and were adjusted for design effects by the method of balanced repeated replications. ${ }^{31}$

\section{RESULTS}

\section{Aggregate Differences in Disorders and the Use of Services}

The aggregate distributions of disorders and use of services in the previous 12 months are shown in Table 1 . The first column of values shows that recent disorders listed in the DSM-III-R, as assessed in these surveys, are significantly more prevalent in the United States (12.0 percent of the respondents had had two or more disorders in the previous 12 months, and 15.7 percent had had one disorder in the previous 12 months) than in Ontario (5.9 percent had had two or more disorders in the previous 12 months, and 12.7 percent had had one disorder in the previous 12 months; $\mathrm{P}<0.001$ ). This difference remained significant in a multivariate analysis that controlled for differences in sociodemographic variables between the two countries.

Table 1 shows that the probability of the use of services for psychiatric problems is also significantly higher in the United States (13.3 percent) than in Ontario $(8.0$ percent, $\mathrm{P}<0.001)$. The shape of the relation between the number and recency of disorders on the one hand and respondents' use of services on the other differs in the two samples $(\mathrm{P}<0.001)$, with the higher rate of use in the United States confined to people in the two lowest categories of the number-and-recency measure. The number of users of services in the United States would decrease by nearly one fourth (from 13.3 percent to 10.2 percent) if
Table 1. Probability of Any Use of Services in the Previous 12 Months and Average Number of Visits According to the Number of DSM-III-R Disorders and How Recently THEY OCCuRRED.

\begin{tabular}{|c|c|c|c|}
\hline $\begin{array}{l}\text { No. AND RECENCY } \\
\text { OF DISORDERS* }\end{array}$ & $\begin{array}{l}\text { DISTRIBUTION } \\
\text { OF DISORDERS }\end{array}$ & $\begin{array}{l}\text { Probability } \\
\text { OF ANy USE } \\
\text { OF SERVICES }\end{array}$ & $\begin{array}{c}\text { AVERAGE } \\
\text { NuMBER OF } \\
\text { VISITS AMONG } \\
\text { USERS }\end{array}$ \\
\hline \multicolumn{4}{|c|}{ percent } \\
\hline
\end{tabular}

United States

In previous $12 \mathrm{mo}$ $\geqslant 2$ Disorders

1 Disorder

History of disorders

No history of disorders

Total

$\begin{array}{rrr}12.0 \dagger & 33.9 & 23.8 \\ 15.7 \dagger & 18.8 & 14.0 \\ 18.3 \dagger & 11.7 \dagger & 16.9 \\ 54.0 \dagger & 7.6 \dagger & 9.4 \\ 100.0 & 13.3 \dagger & 16.0\end{array}$

Ontario

In previous $12 \mathrm{mo}$ $\geqslant 2$ Disorders

1 Disorder

History of disorders

No history of disorders

Total

$\begin{array}{rcc}5.9 \dagger & 39.4 & 20.9 \\ 12.7 \dagger & 17.8 & 13.0 \\ 15.7 \dagger & 7.7 \dagger & 17.7 \\ 65.6 \dagger & 3.3 \dagger & 11.1 \\ 100.0 & 8.0 \dagger & 15.5\end{array}$

*Two or more disorders in previous 12 months denotes that the respondent fulfilled the criteria for two or more of the DSM-III-R disorders assessed in the surveys during the 12 months before the interview; one disorder in previous 12 months denotes that the respondent fulfilled the criteria for one of the DSM-III-R disorders assessed in the surveys during the 12 months before the interview; history of disorders denotes that the respondent did not fulfill the criteria for any disorder in the previous 12 months but did have a history of one or more of the DSM-III-R disorders assessed in the survey at some earlier time; no history of disorders denotes that the respondent never fulfilled the criteria for any of the DSM-III-R disorders assessed in the surveys.

† There was a significant difference between the two countries $(\mathrm{P}=0.05$ by two-tailed test) with control for age, sex, marital status, education, family income (in U.S. dollars), and urbanization.

the rate of use among people in the two lowest categories of the measure were the same as in Ontario. This difference between the two surveys remained significant in a multivariate analysis that controlled for sociodemographic variables.

The results in the third column of values in Table 1 show that there is a generally monotonic and statistically significant relation between the number and recency of disorders and the number of visits among patients in both the United States and Ontario $(\mathrm{P}<0.001)$. There is no statistically significant difference between the two countries in the average number of visits among users of services either in the full sample or in subsamples defined by the number and recency of disorders.

The results in Table 2 show a similar pattern for other measures of the need for services. U.S. respondents reported significantly worse perceived mental health $(\mathrm{P}<0.001)$ and significantly more workdays lost or cut short as a result of psychiatric problems $(\mathrm{P}<0.001)$ than did respondents in Ontario. Furthermore, the significantly higher probability of the use 
Table 2. U.S.-Ontario Odds Ratios for Any Use of Services in the Previous 12 Months According to Other INDICATORS OF NEED.

\begin{tabular}{|c|c|c|c|}
\hline \multirow[t]{2}{*}{ Variable } & \multicolumn{2}{|c|}{$\begin{array}{l}\text { DistRIBUTION OF } \\
\text { INDICATORS OF NEED }\end{array}$} & \multirow[t]{3}{*}{$\begin{array}{l}\text { U.S.-ONTARIO } \\
\text { OddS RATIO FOR } \\
\text { Use OF SERVICES }\end{array}$} \\
\hline & U.S. & ONTARIO & \\
\hline & \multicolumn{2}{|c|}{ percent } & \\
\hline \multicolumn{4}{|c|}{ Perceived mental health } \\
\hline Poor & 0.9 & 0.6 & 2.5 \\
\hline Fair & 6.7 * & 2.9 & $0.8^{*}$ \\
\hline Good & $22.4^{*}$ & 15.9 & $1.2^{*}$ \\
\hline Very good & 38.8 & 41.3 & $2.2^{*}$ \\
\hline Excellent & 31.2 * & 39.4 & 1.8 \\
\hline \multicolumn{4}{|c|}{$\begin{array}{l}\text { Workdays lost in previous } \\
\text { month }\end{array}$} \\
\hline 1 or more & $2.8^{*}$ & 1.4 & 1.3 \\
\hline None & $97.2^{*}$ & 98.6 & $1.7^{*}$ \\
\hline \multicolumn{4}{|c|}{$\begin{array}{l}\text { Workdays cut short in previ- } \\
\text { ous month }\end{array}$} \\
\hline 1 or more & $7.0 *$ & 3.5 & 1.2 \\
\hline None & $93.0^{*}$ & 96.5 & $1.7^{*}$ \\
\hline
\end{tabular}

* There was a significant difference between the countries $(\mathrm{P}=0.05$ by two-tailed test) with control for age, sex, marital status, education, family income (in U.S. dollars), and urbanization. of services in the United States was confined to the subgroup of respondents with low levels of need as defined by each of these indicators.

\section{Use of Services in Separate Sectors}

The disaggregated data presented in Table 3 show that the significantly greater use of the health care sector in the United States than in Ontario was confined to those with no lifetime history of disorders $(\mathrm{P}=0.021)$, whereas the rates of use of the human-services and self-help sectors in the United States were significantly higher than those in Ontario at several levels of illness severity. The rates of use in Ontario were significantly higher than in the United States for general medical treatment of people who had had one $(\mathrm{P}=0.048)$ or more $(\mathrm{P}<0.001)$ disorders in the previous 12 months. According to a desegregated analysis of the average number of visits (results available from the authors), however, there were no significant differences between the two surveys in the average number of visits by patients within any of the treatment sectors at any level of need.

Table 3. Probability of the Use of Services in the Previous 12 Months in Separate Service Sectors According to the Number and Recency OF DSM-III-R DISORDERS.

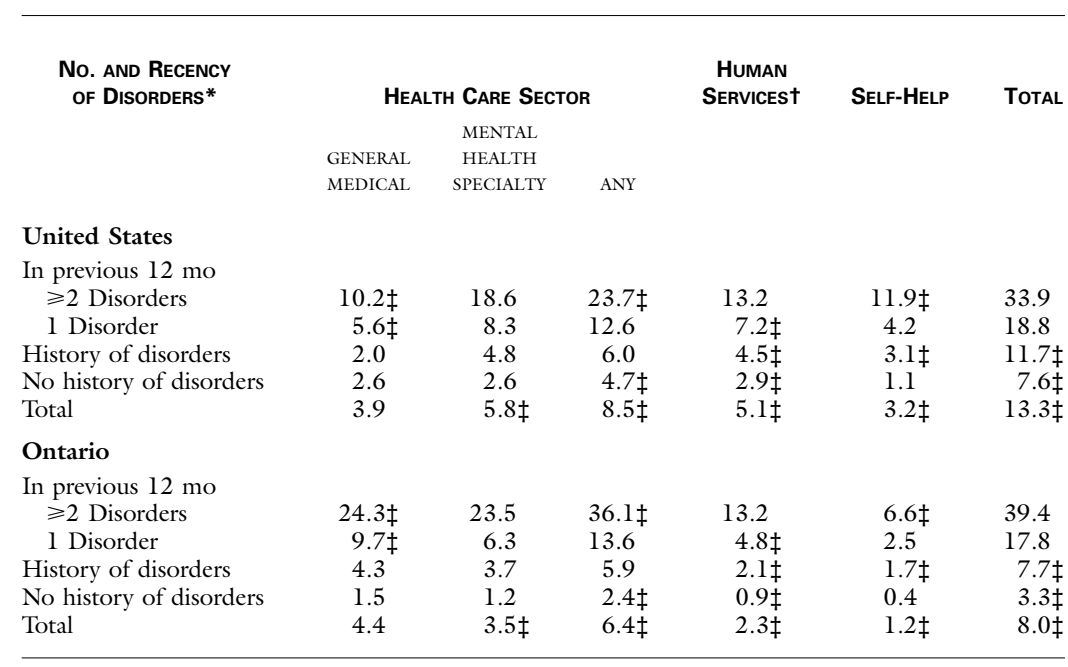

*Two or more disorders in previous 12 months denotes that the respondent fulfilled the criteria for two or more of the DSM-III-R disorders assessed in the surveys during the 12 months before the interview; one disorder in previous 12 months denotes that the respondent fulfilled the criteria for one of the DSM-III-R disorders assessed in the surveys during the 12 months before the interview; history of disorders denotes that the respondent did not fulfill the criteria for any disorder in the previous 12 months but did have a history of one or more of the DSM-III-R disorders assessed in the survey at some earlier time; no history of disorders denotes that the respondent never fulfilled the criteria for any of the DSM-III-R disorders assessed in the surveys.

†The human-services sector includes social services, religious counselors, and other nonmedical professionals.

$\ddagger$ There was a significant difference between the two countries ( $P=0.05$ by two-tailed test) with control for age, sex, marital status, education, family income (in U.S. dollars), and urbanization. 


\section{Role of Nonfinancial System Barriers in Limiting the Use} of Services

The most striking of these results is that the greater use of the health care sector for psychiatric problems in the United States is confined to people with less severe illness. Possibly, professional judgment may enter less heavily into rationing in the United States than in Ontario, although if this were true we would expect that the number of patients without disorders who are seen only once, for evaluation, would be much higher in the United States, but no such difference exists $(\mathrm{P}=0.76)$.

A related possibility is that greater delays in getting treatment among people with transient or mild problems lead to increased self-selection out of the helpseeking process in Ontario. However, this is also inconsistent with the data. Nonusers of services were asked: "Was there ever a time during the past 12 months when you felt that you might need to see a professional because of problems with your emotions or nerves or your use of alcohol or drugs?" More respondents in the United States (8.4 percent) than in Ontario (5.4 percent) responded affirmatively $(\mathrm{P}<0.001)$. We expected that two statements of the reason for this would be endorsed more often in Ontario than in the United States: "I could not get an appointment" and "It would take too much time or be inconvenient." Yet, the first statement was endorsed by only a handful of respondents (13 in the United States and 5 in Ontario), whereas the second was endorsed by more respondents in the United States than in Ontario ( 31.0 percent vs. 19.6 percent of the nonusers with a self-perceived need, $\mathrm{P}<0.001$ ).

\section{Perceptions of Unmet Need and Barriers to Treatment}

A third possibility regarding this difference in the use of health care services between the United States and Ontario is that it is due to a difference in perceived need among people with the same reported number and recency of disorders. This possibility was evaluated by creating a "perceived-need" score that combined the people who reportedly sought help because of perceived need (as opposed to those who involuntarily sought treatment under court order or at the request of their families) with the people who reportedly felt that they needed help but did not get it. Table 4 shows a strong monotonic relation between the number and recency of disorders and this measure of perceived need in both surveys. However, this relation differed significantly in the two surveys $(\mathrm{P}<0.001)$, with perceived need higher in the United States than in Ontario among people with no lifetime history of disorders $(\mathrm{P}<0.001)$ and lower in the United States than in Ontario among people who had had two or more disorders in the previous 12 months $(\mathrm{P}<0.001)$. This same basic pattern emerged when other measures were used to define need (results available from the authors).

As shown in Table 4 , the difference between the two surveys in the relation between disorders and the use of services became insignificant when we adjusted for perceived need. This indicates that perceived need mediates the difference between the surveys in the relation between disorders and the use of services.

\section{DISCUSSION}

\section{Need for Services}

We found that the prevalence of psychiatric problems across all measures of need is higher in the United States than in Ontario - a finding consistent with other evidence of better physical and mental health in Canada than in the United States. ${ }^{5,8,32-35}$ The prevalence rate of DSM-III-R disorders in the NCS is similar to that found in the two-wave consolidated Epidemiologic Catchment Area study, a landmark survey of psychiatric disorders in five U.S. communities that was carried out in the 1980s. ${ }^{36} \mathrm{No}$ comparable earlier survey of Ontario is available with which to compare the estimates of prevalence in the OHS supplement.

Table 4. Probability of the Use of the Health Care Sector IN the Previous 12 Months According to the Number AND Recency of Disorders and the Perceived Need for Professional Help.

No. AND ReCENCY
OF DISORDERS*

United States

In previous $12 \mathrm{mo}$

$\geqslant 2$ Disorders

1 Disorder

History of disorders

No history of disorders

Total

Ontario

In previous $12 \mathrm{mo}$

$\geqslant 2$ Disorders

1 Disorder

History of disorders

No history of disorders

Total

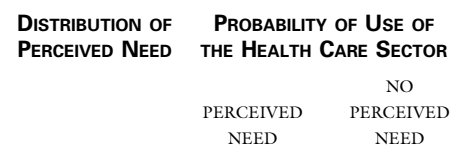

$42.5 \dagger$

26.5

$16.4 \dagger$

$10.3 \dagger$

$17.8 \dagger$

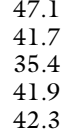

41.7

35.4

42.3

2.1

0.3
0.4

1.1

$\begin{array}{rrr}54.2 \dagger & 56.9 & 11.5 \\ 21.4 & 49.4 & 3.8 \\ 10.7 \dagger & 39.1 & 1.9 \\ 5.3 \dagger & 37.6 & 0.5 \\ 11.1 \dagger & 46.2 & 1.4\end{array}$

*Two or more disorders in previous 12 months denotes that the respondent fulfilled the criteria for two or more of the DSM-III-R disorders assessed in the surveys during the 12 months before the interview; one disorder in previous 12 months denotes that the respondent fulfilled the criteria for one of the DSM-III-R disorders assessed in the surveys during the 12 months before the interview; history of disorders denotes that the respondent did not fulfill the criteria for any disorder in the previous 12 months but did have a history of one or more of the DSM-III-R disorders assessed in the survey at some earlier time; no history of disorders denotes that the respondent never fulfilled the criteria for any of the DSM-III-R disorders assessed in the surveys.

†There was a significant difference between the two countries $(\mathrm{P}=0.05$ by two-tailed test) with control for age, sex, marital status, education, family income (in U.S. dollars), and urbanization. 
There are a number of plausible substantive explanations for the higher prevalence of psychiatric problems in the United States than in Ontario, such as the possibility of higher exposure to stress or lower access to supportive social networks. At least three plausible methodologic hypotheses can also be advanced, but analyses of the available data do not support them. First, the burden associated with the earlier stage of assessment in the OHS, which involved one household informant reporting on the health of all household members and each household member being asked to complete a personal health questionnaire, led to a higher rate of denial in the OHS supplement. However, subgroup analyses failed to find any meaningful relation between the reported presence of psychiatric disorders in the supplement and either the level of involvement in or the time elapsed since the OHS.

The second methodologic hypothesis is that Ontario's lower rate of response was associated with fewer psychiatrically impaired respondents. However, the results of NCS subgroup analyses are inconsistent with this hypothesis: there is only a small difference in the prevalence of disorders between the subgroup of easy-to-recruit respondents and the total sample. ${ }^{28}$

The third methodologic hypothesis is that the NCS commitment probe prompted a more serious memory search among respondents than the supplement, thereby inflating the estimated prevalence of DSM-III-R disorders in the NCS. However, this hypothesis is inconsistent with the results of a methodologic analysis that found similar levels of role impairment associated with a given category of the measure of the number and recency of disorders for the two surveys. Furthermore, the same pattern of results emerged when we studied differences between the surveys in perceived mental health, which was assessed before the commitment probe was administered, and in work impairment, which was assessed long after the commitment probe was administered.

\section{The Relation between Need and the Use of Services}

The most interesting of our findings is that the higher probability of treatment in the United States is confined to those with low levels of need. Further analysis suggests that this difference is due to a higher probability of a perceived need for treatment. This result, however, is based on retrospective reports. Furthermore, the possibility that it is due to a methodologic difference between the surveys cannot be unequivocally excluded; for example, general practitioners in Ontario might be more likely than their U.S. counterparts to treat minor psychiatric problems in a way that does not force patients to realize that their problems are emotional, in which case the actual use of services for psychiatric prob- lems might be underreported in Ontario as compared with the United States among patients with low levels of need for services.

\section{Overview}

Given these methodologic cautions, our findings suggest that psychiatric problems are more prevalent in the United States than in Ontario and that the higher probability of use of services in the United States is confined to those with low levels of need for services. No data are presented here on the comparative efficacy of treatments, so it is not possible to draw conclusions about whether one system is better than the other; other dimensions of need not assessed in these surveys might show a different pattern of differences between the two countries in the allocation of resources. Nonetheless, the measures of need considered here are clearly important ones, and the data show that the delivery of services could be improved with regard to these measures if services were allocated in the United States as they are in Ontario.

Direct controls on providers appear to be insignificant in explaining this difference in allocation, because there is neither any difference in the average number of visits nor any evidence that nonfinancial barriers, such as long waiting lists, deter Canadians from seeking treatment. Rather, the difference appears to be at the point of the patient's decision to seek treatment. A preliminary analysis suggests that a higher probability of perceived need for treatment among U.S. residents with less severe illness is probably a critical variable. Why this difference exists is uncertain. One possibility is that the Canadian health care system is more effective than the U.S. system in educating patients about the appropriate level of need required to justify seeking help, or perhaps stoicism is cultivated more generally at earlier periods of socialization in Ontario than in the United States. These or other plausible hypotheses cannot be evaluated with the present data. Nonetheless, the results suggest that any plan to expand access to mental health services in the United States must contend with the problem of demand by people with low levels of need for services.

The National Comorbidity Survey, a collaborative investigation of the prevalence, causes, and consequences of psychiatric disorders in the United States, is supported by grants (MH46376, MH52861, and MH49098) from the National Institute of Mental Health and by a supplement from the National Institute of Drug Abuse (to MH46376) and a grant from the W.T. Grant Foundation (90135190). Preparation of this report was also supported by a Research Scientist Award to Dr. Kessler (MH00507) and a Robert Wood Johnson Generalists Faculty Scholar Award to Dr. Katz (026894). The Mental Health Supplement to the Ontario Health Survey, an epidemiologic survey designed to assess the prevalence of psychiatric disorders and associated risk factors, disabilities, and use of services across the Province of Ontario, is supported by the Ontario Ministries of Health and Community and Social Services through the Ontario Mental Health Foundation. 


\section{APPENDIX}

The following sites and investigators collaborated in the National Comorbidity Survey: Addiction Research Foundation - R. Room; Duke University Medical Center - D. Blazer and M. Swartz; Harvard University - R. Frank and R. Kessler; Johns Hopkins University - J. Anthony, W. Eaton, and P. Leaf; University of Miami - R.J. Turner; Max Planck Institute of Psychiatry-Clinical Institute - H.-U. Wittchen; Medical College of Virginia - K. Kendler; University of Michigan L. Johnston, S. Katz, R. Kessler, and R. Little; New York University P. Shrout; State University of New York-Stony Brook - E. Bromet; and Washington University School of Medicine - L. Cottler and A. Heath. The following agencies and investigators collaborated in the Mental Health Supplement to the Ontario Health Survey: Ontario Mental Health Foundation - D. Campbell; Clarke Institute of Psychiatry - P. Goering and E. Lin; McMaster University - M. Boyle and D. Offord; and the Ontario Ministry of Health - G Catlin.

\section{REFERENCES}

1. Hollingsworth EJ. Falling through the cracks: care of the chronically mentally ill in the United States, Germany, and the United Kingdom. J Health Polit Policy Law 1992;17:899-928

2. Frank RG, McGuire TG. A review of studies of the impact of insurance on the demand and utilization of specialty mental health services. Health Serv Res 1986;21:241-65.

3. Bigelow DA, McFarland $\mathrm{BH}$. Comparative costs and impacts of Canadian and American payment systems for mental health services. Hosp Community Psychiatry 1989;40:805-8.

4. Evans RG. Canada: the real issues. J Health Polit Policy Law 1992;17: 739-62.

5. Fuchs VR. The best health care system in the world? JAMA 1992;268: 916-7.

6. Barer ML, Evans RG. Interpreting Canada: models, mind-sets, and myths. Health Aff (Millwood) 1992;1 (1):44-61.

7. Statistics Canada. Canada year book 1990. Ottawa, Ont.: Supply and Services Canada, 1989

8. Bureau of the Census. Statistical abstract of the United States 1994 Washington, D.C.: Government Printing Office, 1994.

9. Health personnel in Canada 1990. Ottawa, Ont.: Health and Welfare Canada, 1992

10. Roback G, Randolph L, Seidman B. Physician characteristics and distribution in the U.S. Chicago: American Medical Association, 1992.

11. Macnaughton E. Towards rebalancing Canada's mental health system. In: Community investment. Vol. 2. Toronto: Canadian Mental Health Association, 1991

12. Ontario Ministry of Health. Putting people first: the reform of mental health services in Ontario. Toronto: Queen's Printer for Ontario, 1993 13. Rochefort DA. More lessons, of a different kind: Canadian mental health policy in comparative perspective. Hosp Community Psychiatry 1992;43:1083-90.

14. Freeman SJJ. An overview of Canada's mental health system. In: Bachrach LL, Goering P, Wasylenki D, eds. Mental health care in Canada. San Francisco: Jossey-Bass, 1994:11-20.

15. Frank RG, McGuire TG. Health reform and financing of mental health services: distributional issues. In: Manderscheid RW, Sonnenscheim MA eds. Mental health, U.S., 1994. Washington, D.C.: Government Printing Office, 1994:8-20. (DHHS publication no. (SMA) 94-3000.)
16. Kessler RC, McGonagle $\mathrm{KA}, \mathrm{Zhao} S$, et al. Lifetime and 12-month prevalence of DSM-III-R psychiatric disorders in the United States: results from the National Comorbidity Survey. Arch Gen Psychiatry 1994;51:819.

17. Robins LN, Regier DA, eds. Psychiatric disorders in America: the epidemiologic catchment area study. New York: Free Press, 1991.

18. Mental health and substance abuse benefits survey, research and survey services. Princeton, N.J.: A. Foster Higgins, 1990.

19. Offord DR, Boyle M, Campbell D, et al. Mental health in Ontario: selected findings from the Mental Health Supplement to the Ontario Health Survey. Toronto: Queen's Printer for Ontario, 1994

20. Fischer PJ, Breakey WR. The epidemiology of alcohol, drug, and mental disorders among homeless persons. Am Psychol 1991;46:1115 28.

21. Clarke Institute Consulting Group. Estimating the utilization of inpatient beds in a reformed system of care: a report to the Ontario Ministry of Health. Toronto: Clarke Institute of Psychiatry, 1994.

22. Jahiel RI. The size of the homeless population. In: Jahiel RI, ed. Homelessness: a prevention-oriented approach. Baltimore: Johns Hopkins University Press, 1992:337-57.

23. Composite International Diagnostic Interview (CIDI), version 1.0 Geneva: World Health Organization, 1990.

24. Wittchen H-U. Reliability and validity studies of the WHO-Composite International Diagnostic Interview (CIDI): a critical review. J Psychiatr Res 1994;28:57-84.

25. Cannell CF, Miller PV, Oksenberg L. Research on interviewing techniques. In: Leinhardt S, ed. Sociological methodology 1981. San Francisco: Jossey-Bass, 1981:389-437.

26. Cannell CF, Marquis KH, Laurent A. A summary of studies of interviewing methodology. Vital and health statistics Series 2. No. 69. Rockville, Md.: National Center for Health Statistics, Health Resources Admin istration, 1977. (DHEW publication no. (HRA) 77-1343.)

27. George LK. Health services validation data: preliminary results: Duke ECA working paper. Durham, N.C.: Duke University, 1985.

28. Kessler RC, Little RJA, Groves RM. Advances in strategies for minimizing and adjusting for survey nonresponse. Epidemiol Rev 1995;17:192204.

29. Woodruff RS, Causey BD. Computerized method for approximating the variance of a complicated estimate. J Am Stat Assoc 1976;71:315-21. 30. OSIRIS VII. Ann Arbor: University of Michigan Institute for Social Research, 1981

31. Kish L, Frankel MR. Balanced repeated replications for standard errors. J Am Stat Assoc 1970;65:1071-94.

32. Katz A, McCarry M. A tale of two systems: a comparative study of the British Columbia and Washington State health care systems and their effects on access, cost, and health. Seattle: University of Washington School of Public Health and Community Medicine, Department of Health Services, Health Policy Analysis Program, 1989.

33. Roos L, Fisher ES, Brazauskas R, Sharp SM, Shapiro E. Health and surgical outcomes in Canada and the United States. Health Aff (Millwood) $1992 ; 11(2): 56-72$

34. Suicide rates and figures, 1950-1992. Ottawa: Statistics Canada, 1994 35. International profile 1994: alcohol and other drugs. Toronto: Alcoholism and Drug Research Foundation, 1994.

36. Regier DA, Narrow WE, Rae DS, Manderscheid RW, Locke BZ, Goodwin FK. The de facto US mental and addictive disorders service system: epidemiologic catchment area prospective l-year prevalence rates of disorders and services. Arch Gen Psychiatry 1993;50:85-94. 